\title{
Espaços da imigração internacional em São Paulo: uma análise do período recente.
}

\section{Luis Felipe Foiadelli, Natália Demétrio, Rosana Baeninger}

\section{Resumo}

Inserido no projeto Observatório das Migrações em São Paulo (NEPO/UNICAMP), coordenado pela Prof ${ }^{a}$ Dra Rosana Baeninger, essa pesquisa tem por objetivo avançar no conhecimento teórico, metodológico e empírico da imigração internacional contemporânea para o estado de São Paulo, com ênfase no município de Campinas. Devido aos desafios de se construir indicadores que avancem nas dimensões descritivas da dinâmica migratória em termos de entradas, saídas e rotatividade (BAENINGER, 2012) ${ }^{1}$ para além do Censo Demográfico (o mais completo levantamento sóciodemográfico do país, apresentando uma riqueza plural de informações da migração internacional) é utilizado registros administrativos, principalmente o da Prefeitura de Campinas, a fim de preencher as lacunas das bases de dados nos períodos intercensitários.

\section{Palavras-chave:}

Migração, Campinas, Políticas Sociais.

\section{Introdução}

Para entender as transformações do fluxo imigratório e as novas modalidades migratórias no Brasil é importante dialogar com as mudanças estruturais na geopolítica e na economia brasileira, como a reestruturação produtiva conduzida pelo capital financeiro e como a divisão internacional do trabalho se altera (HARVEY, 1992; SASSEN, 19983), o fortalecimento das relações Sul-Sul (MANRIQUE, 2012) ${ }^{4}$, o crescimento econômico brasileiro na primeira década dos anos 2000 (MANRIQUE, 2012) ${ }^{4}$ e o enrijecimento das políticas migratórias nos países desenvolvidos (MÁRMORA, 20105; BASSO, 20136).

\section{Resultados e Discussão}

$\mathrm{Na}$ Tabela 1, foram utilizados dados do Censo Demográfico (1920-2010) a fim de mensurar o estoque de imigrantes no estado de São Paulo e na cidade de Campinas. Apesar da redução dos imigrantes internacionais tanto no estado de São Paulo quanto na cidade de Campinas, outras nacionalidades aparecem mesmo não apresentando nenhuma relação histórica com o país. O mapa 1 evidencia a localização dos imigrantes a partir das fichas cadastradas no Serviço ao Imigrante, Refugiado e Apátrida de Campinas, entre 2015 e 2017 os imigrantes cadastrados no serviço se concentravam na cidade de Campinas nas regiões: Barão Geraldo e Centro.

Tabela 1. Evolução da população total e de imigrantes internacionais, Estado de São Paulo e Campinas, $1920,1940,1950,1970,1980,1991,2000,2010$.

\begin{tabular}{c|c|c|c|c|c|c}
\hline \multirow{2}{*}{ Ano } & \multicolumn{3}{|c|}{ Estado de São Paulo } & \multicolumn{3}{c}{ Campinas } \\
\cline { 2 - 7 } & População total & Imigrantes internacionais & $\%$ & População total & $\begin{array}{c}\text { Imigrantes } \\
\text { internacionais }\end{array}$ & $\%$ \\
\hline 1920 & 4.592 .188 & 829.851 & 18,1 & 115.602 & 23.416 & 20,3 \\
1940 & 7.180 .316 & 814.102 & 11,3 & 129.940 & 9.360 & 7,2 \\
1950 & 9.134 .423 & 693.321 & 7,6 & 152.547 & 9.317 & 6,1 \\
1970 & 17.958 .693 & 703.526 & 3,9 & 372.067 & 8.616 & 2,3 \\
1980 & 25.375 .199 & 523.444 & 2,1 & 661.992 & 8.958 & 1,4 \\
1991 & 31.546 .473 & 414.263 & 1,3 & 843.516 & 9.796 & 1,2 \\
2000 & 36.969 .476 & 343.944 & 0,9 & 966.700 & 7.848 & 0,8 \\
2010 & 41.262 .199 & 266.781 & 0,6 & 1.080 .113 & 6.250 & 0,6 \\
\hline
\end{tabular}

Fonte: Instituto Brasileiro de Geografia e Estatística (IBGE), Censos Demográficos 1920, 1940, 1950, 1970, 1980, 1991, 2000 e 2010. Tabulações Observatório das Migrações em São Paulo NEPO/UNICAMP.

Mapa 1. Atendimentos realizados pelo Serviço de Referência ao Imigrante, Refugiado e Apátrida da Prefeitura Municipal de Campinas, segundo local de residência em Campinas e região (2015 a 2017)

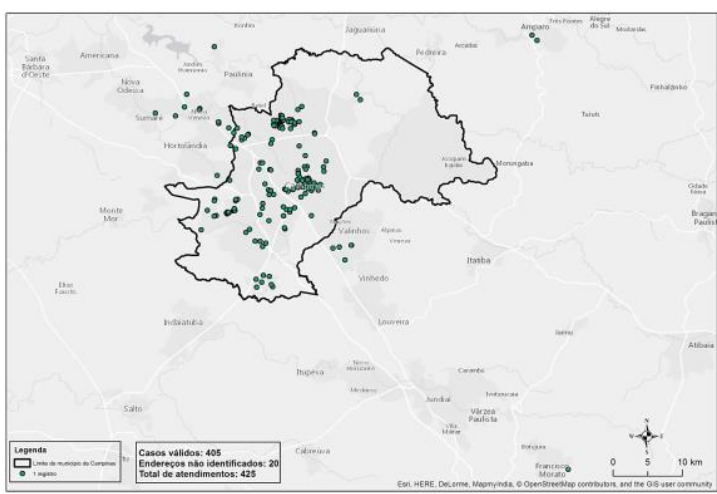

Fonte: Fonte: Serviço de Referência ao Imigrante, Refugiado e Apátrida da Prefeitura Municipal de Campinas, Secretaria de Secretaria Municipal dos Direitos da Pessoa com
Deficiência e Cidadania, 2015 a 2017. Tabulações Observatório das Migrações em São Paulo - NEPO/UNICAMP-Fapesp/CNPq.

\section{Conclusões}

A partir das leituras feitas e dos dados obtidos e sistematizados, é possível compreender o papel de Campinas na rota das migrações internacionais sul-sul $(B A E N I N G E R, 2018)^{7}$, no qual, cada vez mais será necessário desenhar políticas sociais voltadas para os imigrantes, a fim de reduzir as desigualdades, reestruturando suas vidas desde 0 acesso a documentação a inserção no mercado de trabalho.

\section{Agradecimentos}

Ao $\mathrm{CNPq}$ pela bolsa, ao Serviço de Referência ao Imigrante, Refugiado e Apátrida e ao NEPO/UNICAMP.

\footnotetext{
1 BAENINGER, R. Fases e faces da migração em São Paulo. 2012. 146 p Tese (Livre-docência) - Núcleo de Estudos de População, Universidade Estadual de Campinas, Campinas, 2012.

${ }^{2}$ HARVEY, D. Condição pós-moderna: uma pesquisa sobre as origens da mudança cultural. São Paulo: Edições Loyola, 1992.

${ }^{3}$ SASSEN, S. As cidades na economia mundial. São Paulo: Studio Nobel 1998.

${ }^{4}$ MANRIQUE, L. E. El emergente eje "Sur-Sur" global. Política Exterior, marzo/abril de 2012.

${ }^{5}$ MÁRMORA, L. Modelos de Governabilidad Migratoria. La perspectiva política en América del Sur .Revista Interdisciplinar de Mobilidade Humana, Brasília, Ano XVIII, No 35, p. 71-92, jul./dez. 2010

${ }^{6}$ BASSO, R. Imigração, racismo e antirracismo na Europa hoje. In TAVARES, M. A.; GOMES, C. (Org). Intermitências da Crise e Questão Social: uma interpretação marxista. João Pessoa: Editora UFPB, 2013, p.83133

${ }^{7}$ BAENINGER, R. CONTRIBUIÇÕES DA ACADEMIA PARA O PACTO GLOBAL DA MIGRAÇÃO: O OLHAR DO SUL. In: BAENINGER, Rosana; BÓGUS, Lúcia Machado; MOREIRA, Júlia Bertino. MIGRAÇÕES SULSUL. 2. ed. Campinas: Unicamp, 2018. p. 17-22.
} 